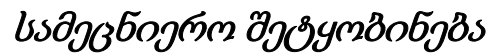

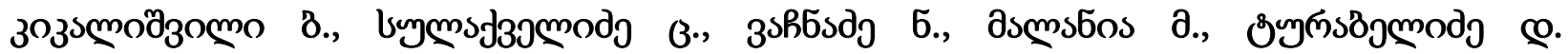

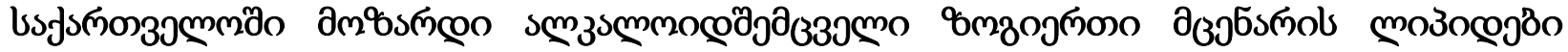

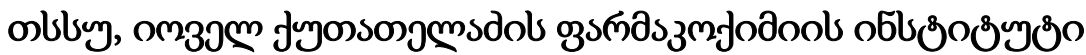

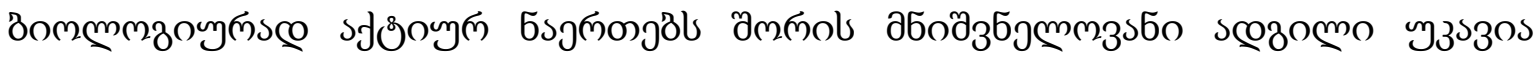

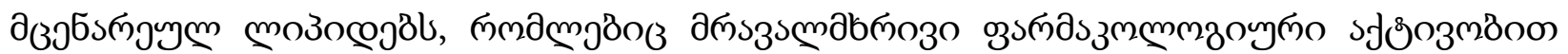

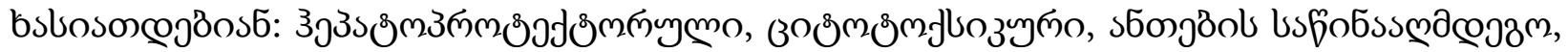

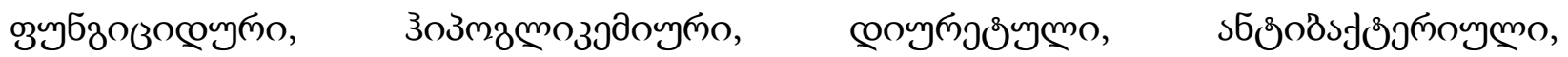

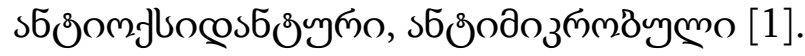

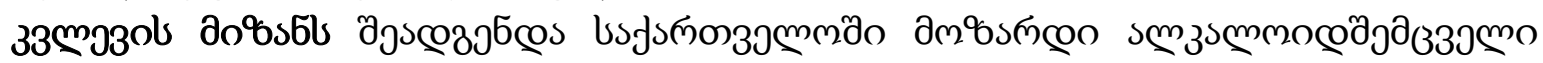

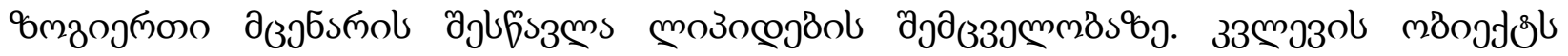

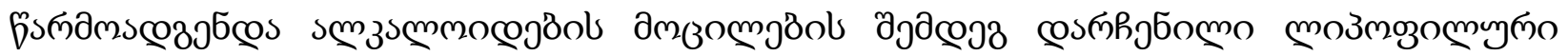

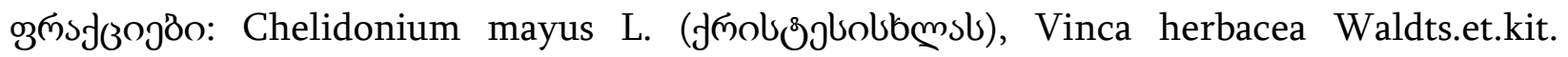

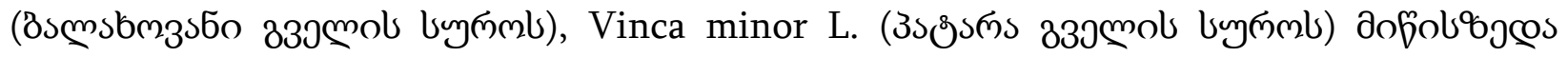

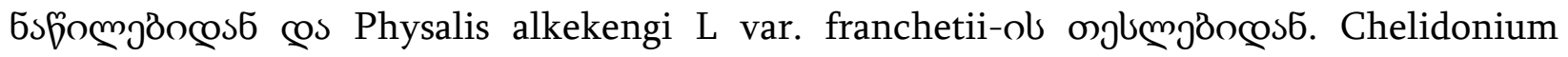

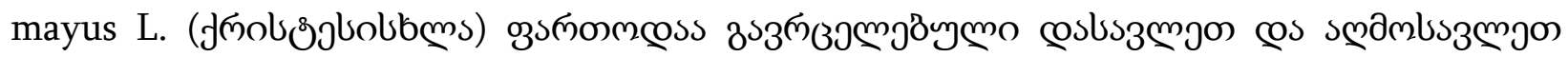

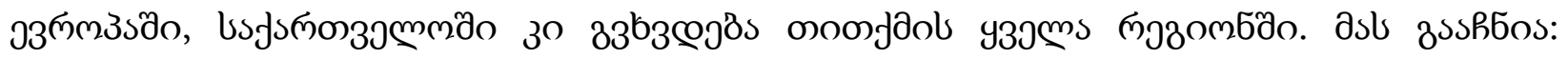

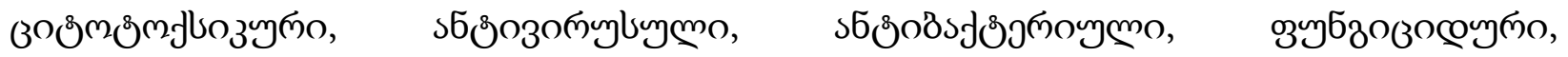

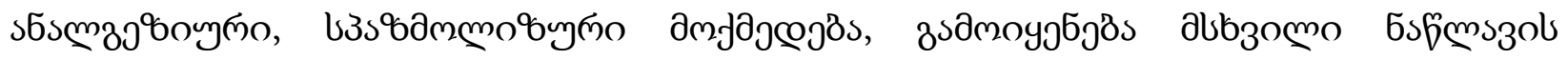

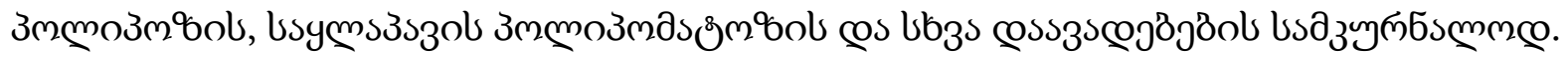

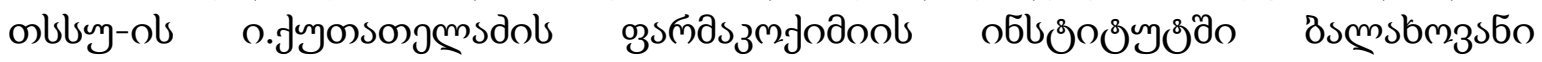

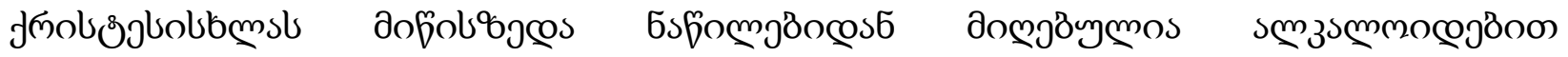

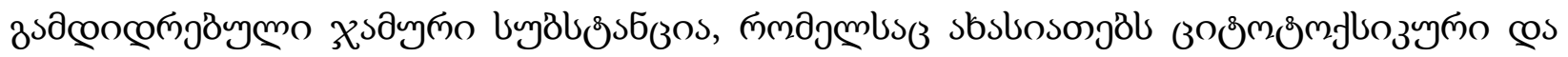

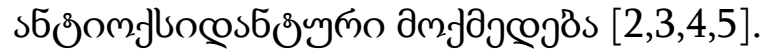

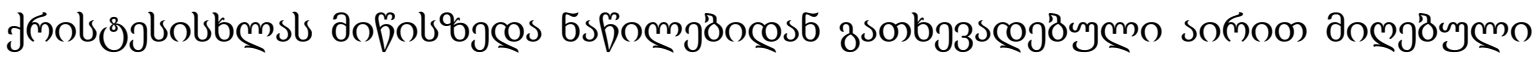

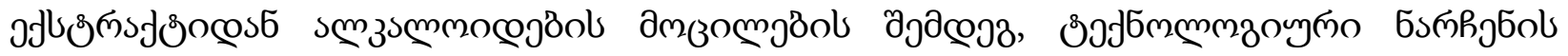

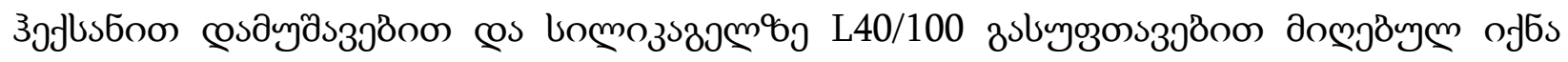

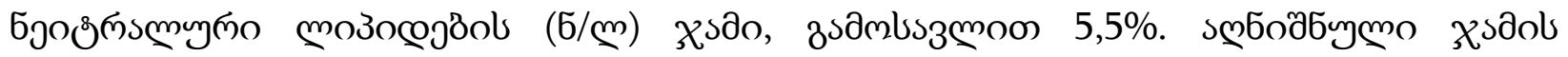

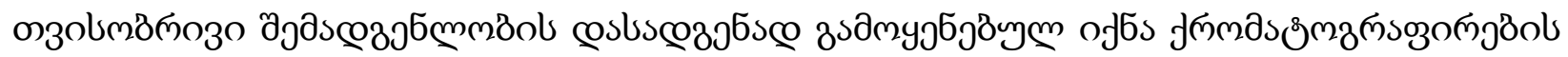

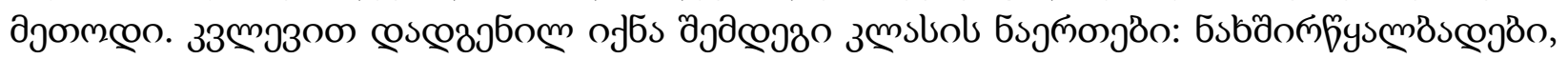

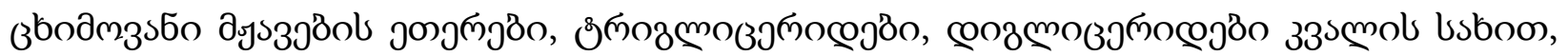

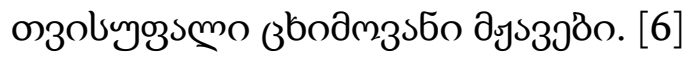

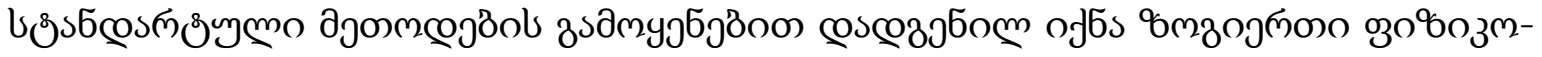

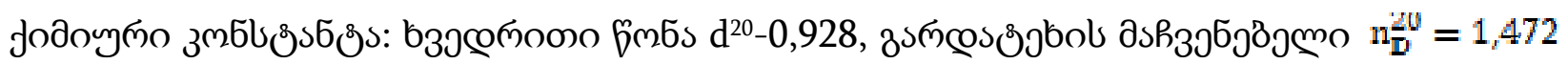
omeols no 3 b3o I2-106,7.

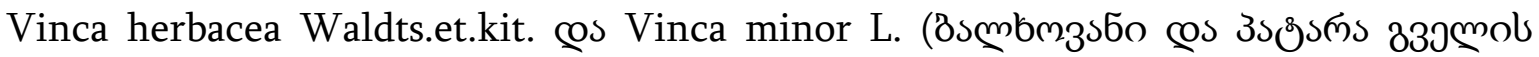

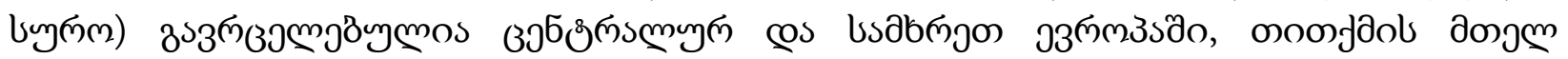

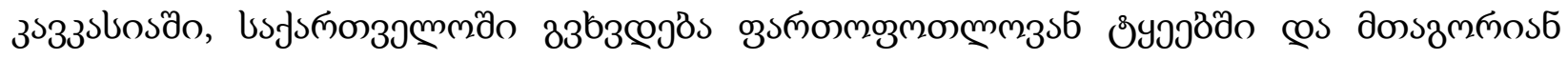

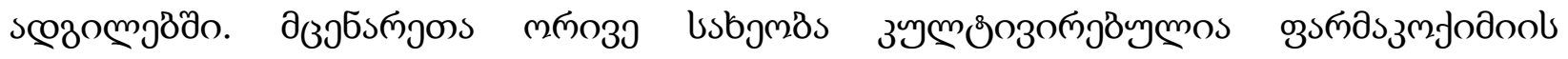

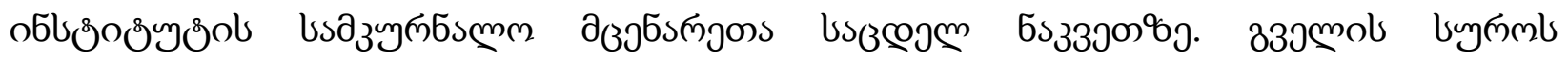




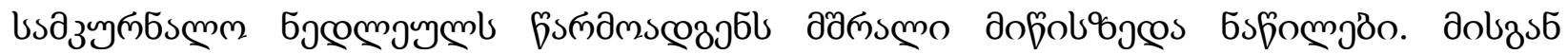

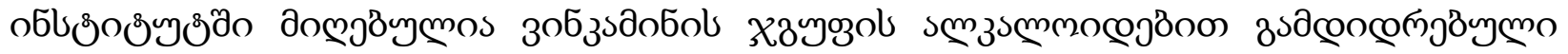

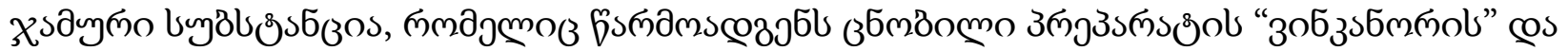

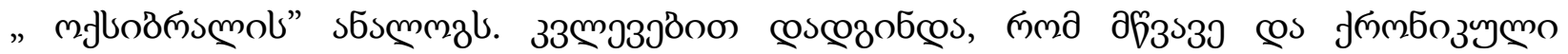

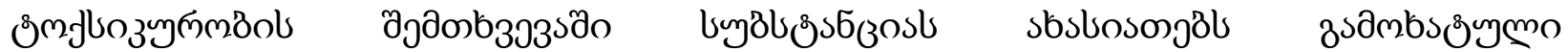

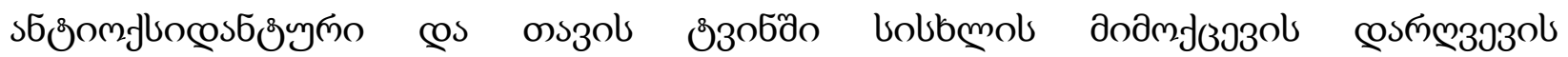

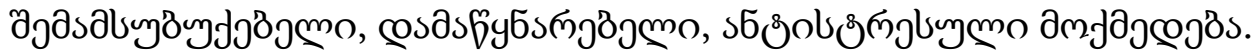

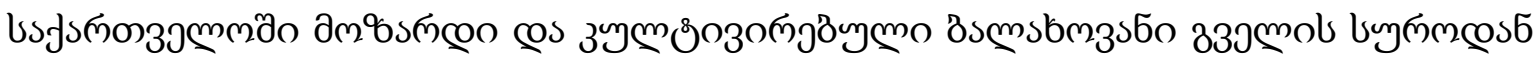

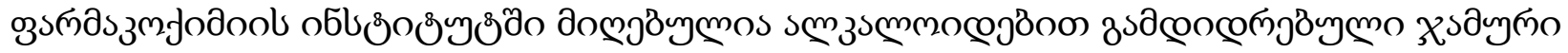

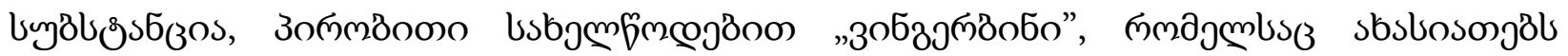

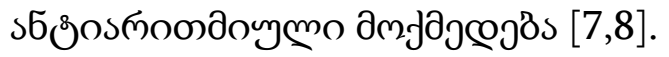

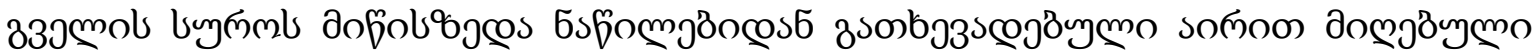

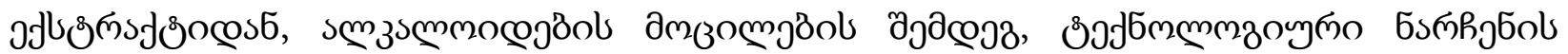

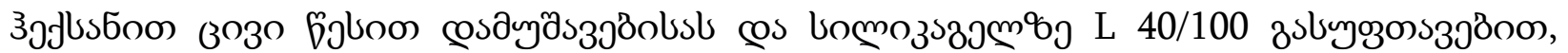

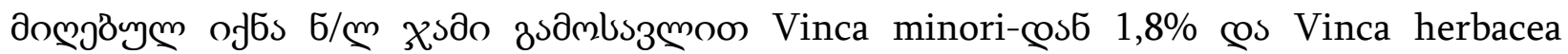

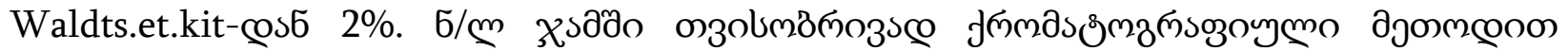

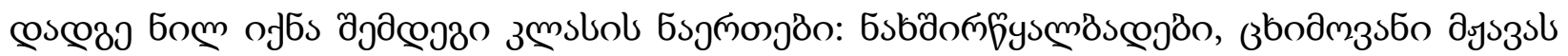

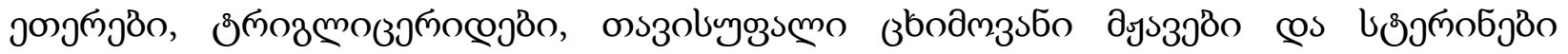
з3s mols bsbon.

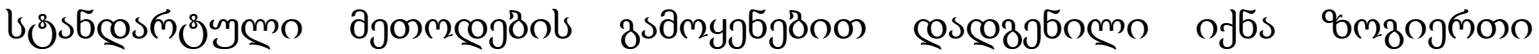

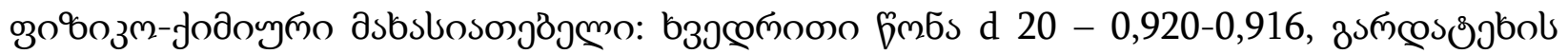

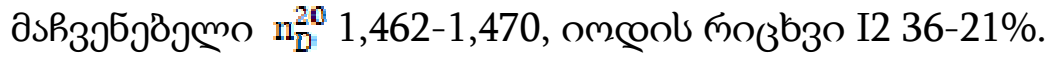

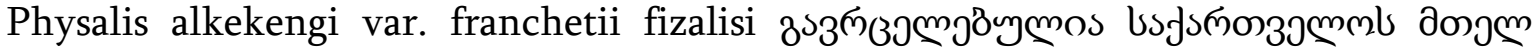

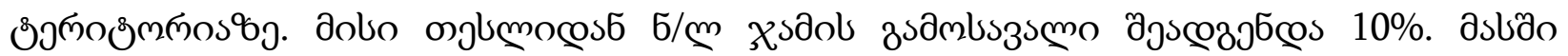

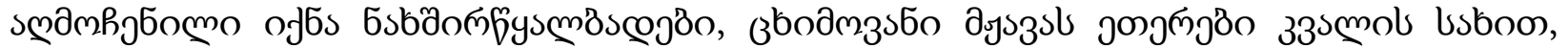

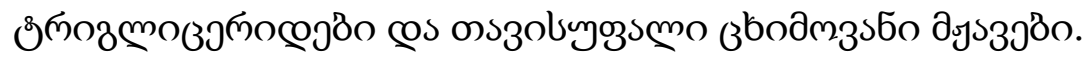

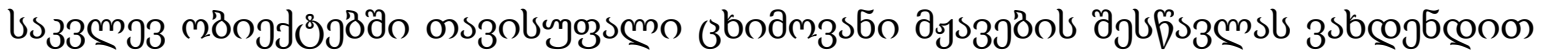

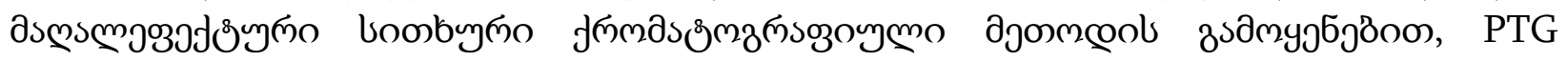

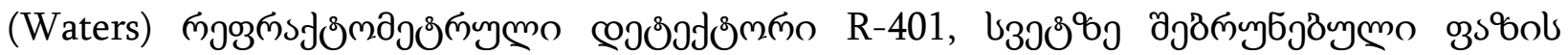

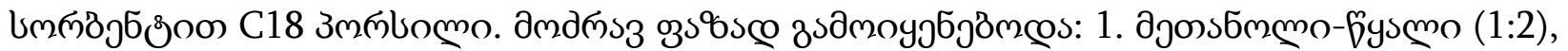

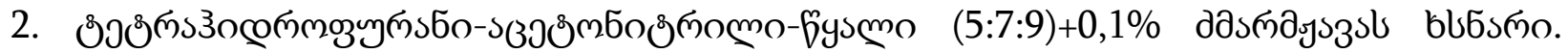

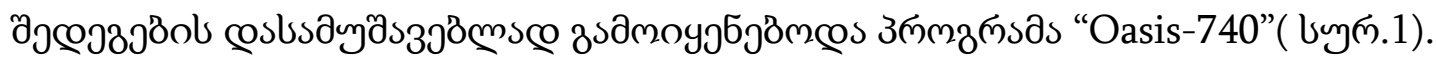




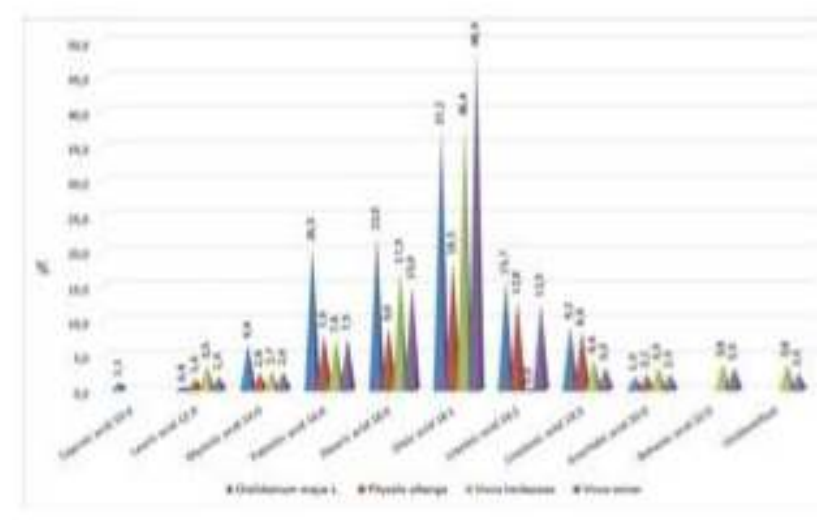

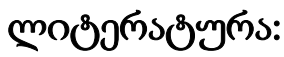

1. С.М. Адекенов. Новые оригинальные фитопрепараты. Перспективы применения в медицине и организация их производства. Конференция „Фармация Казахстана., 2009,т.1,с.201-208.

2. Б. Ю.Кикалишвили. В. Ю. Вачнадзе. Алкалоиды Chelidonium majus L. произрастающего в Грузии. Georgian Medical News, 2003, v.3, . № 4 с. 362-366.

3. Б.Ю.Кикалишвили. Н.С..Вачнадзе, В.Ю. Вачнадзе. Хроматоспектро фотометрическая методика количественного определения хелид онина в траве

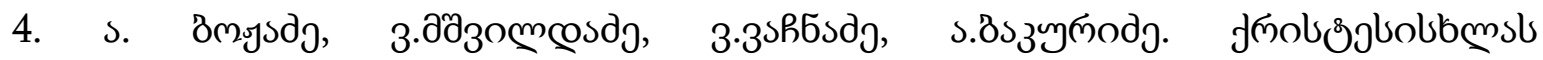

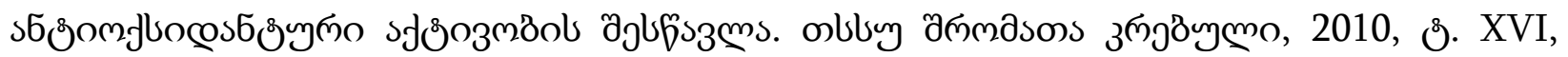
33.17-19.

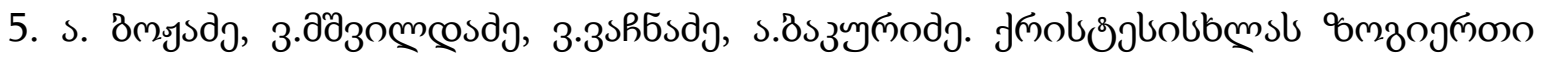

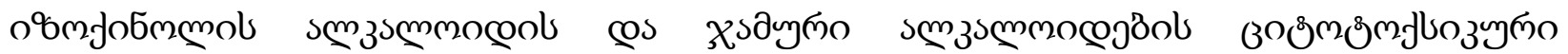

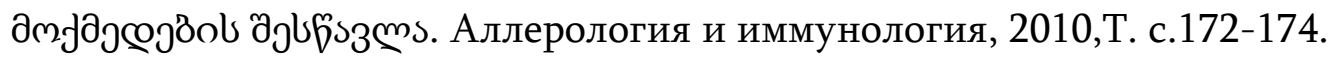

6. Зурабашвили 3.А., Сунозова Е.В., Хроматографический анализ жиров и масел. М.:2010,74. Гагуа Н.Д., Бакуридзе А.Дж., Вачнадзе Н.С., Берашвили Д.Т., Вачнадзе В.Ю. Изучение процесса экстракции фармакологически активных алкалоидов из видов Vinca. Georgian Medical News, 2011, c.185.

8. Гагуа Н.Д., Чхиквадзе Г.В., Вачнадзе Н.С., Вачнадзе В.Ю. Бакуридзе А.Дж., Вингербин сумарный препарат индолиновых алкалоидов из Vinca herbacea W.et.kit. с антиаритмической активностью. Аллергология и иммунология. 2010. Том11. №2.

\section{scientific information}

Kikalishvili B., Sulakvelidze Ts.,Vachnadze N., Malania M., Turabelidze D. LIPIDS OF SOME ALKALOID-CONTAINING PLANTS GROWING IN GEORGIA TSMU, KUTATELADZE INSTITUTE OF PHARMACOCHEMISTRY

Crude neutral lipids were obtained from aerial parts of alkaloid-containing plants Chelidoniummayus L, VincaherbaceaWaldts. et.kit, Vinca minor L. Physalisalkekengi L var. franchetii, growing in Georgia and their qualitative composition was established. As well free fatty acids were identified quantitatively and qualitatively using HPLC. 